\title{
CRACK COCAINE USE AND ITS RELATIONSHIP WITH VIOLENCE AND HIV
}

\author{
Heraclito Barbosa de Carvalho, ${ }^{\mathrm{I}}$ Sergio Dario Seibel ${ }^{\mathrm{II}}$ \\ doi: 10.1590/S1807-59322009000900006
}

Carvalho HB, Seibel SD. Crack cocaine use and its relationship with violence and HIV. Clinics. 2009;64(9):857-66.

OBJECTIVES: To evaluate crack cocaine use practices, risk behaviors associated with HIV infection among drug users, and their involvement with violence.

INTRODUCTION: HIV infections are frequent among drug users due to risky sexual behavior. It is generally accepted that crack cocaine use is related to increased levels of violence. Several reports point to an increase in violence from those involved in drug trafficking. Although HIV infections and risky sexual behavior among drug users have been quite well studied, there are few studies that evaluate violence as it relates to drugs, particularly crack.

METHODS: A total of 350 drug users attending drug abuse treatment clinics in São Paulo, Brazil were interviewed about their risky behaviors. Each patient had a serological HIV test done.

RESULTS: HIV prevalence was 6.6\% (4.0 to 10.2). Violence was reported by $97 \%$ (94.7 to 99.1 ) of the subjects (including cases without personal involvement). Acts of violence such as verbal arguments, physical fights, threats, death threats, theft, and drug trafficking were significantly higher among crack users. A decrease in frequency of sexual intercourse was observed among users of injected drugs, though prostitution was observed as a means of obtaining drugs. A high number of crack cocaine users had a history of previous imprisonment, many for drug-related infractions.

DISCUSSION: The data presented are in accordance with other reports in the literature, and they show a correlation between drug use, imprisonment, violence, and drug trafficking.

CONCLUSION: A high HIV prevalence and associated risky sexual behaviors were observed among crack cocaine users. The society and the authorities that deal with violence related to crack users and drug trafficking should be aware of these problems.

KEYWORDS: HIV; Drug use; Crack cocaine; Risk behavior; Violence.

\section{INTRODUCTION}

Drug users are a group that deserves special attention by the health care system, due to their high rates of exposure to infections, particularly those transmitted through the use of contaminated materials (syringes, needles and related components) and through unprotected sexual intercourse. In addition to the increased individual risk of acquiring these infections, drug users play an important role in the

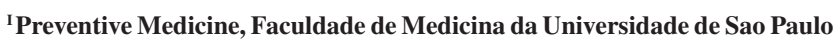
- São Paulo/SP, Brazil.

II Legal Medicine, Faculdade de Medicina da Universidade de Sao Paulo São Paulo/SP, Brazil.

Email: heracc@usp.br

Tel.: 55113061.7444

Received for publicaiton on May 22, 2009

Accepted for publication on June 26, 2009 transmission of diseases in their communities. ${ }^{1-3}$ The current AIDS pandemic is the most dramatic example of this.

The use and abuse of illegal drugs appears to be associated with drug trafficking and violence. ${ }^{4}$ There is growing evidence to support the role of drugs in the spread of violence. ${ }^{4,5}$ The types of drugs used vary according to region of the world. In many countries, such as Thailand, the United States, and some European nations, heroin is easily accessible, but it is not as easily available in most of countries in South America. ${ }^{6}$ The 1990s saw a rise in crack cocaine abuse throughout most of the world, ${ }^{6,70}$ and the literature currently indicates that marijuana and cocaine are the most marketed drugs worldwide.

The use of crack cocaine, or crack, was first reported in 1980 in Europe and the US ${ }^{7}$ as a new drug with quick, stimulating effects. Crack cocaine is a byproduct of cocaine, obtained from the leaves of a shrub named Erythroxylon 
coca. The refining process begins with the transformation of the leaves into a product known as basic cocaine paste (BCP). The paste can then be turned into either crack cocaine through chemical treatment with sodium bicarbonate, or into a white powder (cocaine) when it is refined with ether acetone or sulfuric and hydrochloric acids. In its powdered form, the drug can be inhaled, used orally or intravenously; the paste (basuko, merla) and rock (crack cocaine) forms can be smoked either on their own or together with tobacco or cannabis-marijuana (pitillos or mesclado). The powdered and rock forms of the drug are less costly, albeit far more virulent and harmful to health. ${ }^{7}$

According to information from federal and state authorities, as well as field studies and clinical reports, crack cocaine abuse in Brazil is on the rise..$^{3,8-10}$ The use of crack in Brazil began in 1989, in the city of São Paulo. ${ }^{8}$ In the 1980 s and early 1990 s, the shift from cocaine to crack, as well as the increased use of crack, was noted in a number of reports. ${ }^{9,10}$ Over that time, the drug become one of the main illegal drugs consumed in the city of São Paulo, with a prevalence as high as $65 \%$ in $1995-1997 .{ }^{11}$ In the city of Santos (SP), the reported use of crack cocaine by injection drug users (IDUs) increased from $10 \%$ in 1991 to $60 \%$ in 1996. ${ }^{12,13}$

Violence also seems to be associated with the use and illegal trafficking of illicit drugs - a fact that has received great attention in the media. Beato Filho et al. ${ }^{14}$ observed, in a study on the number of homicides in Belo Horizonte (MG), that violence is associated with a low economic and social profile, as well as with drug trafficking. A study by Inciardi ${ }^{15}$ shows that homelessness among boys and girls prompts drug abuse and violence. ${ }^{15}$ However, there have been no other reports on the association between drugs and violence in Brazil. As a result, there is a need to evaluate this matter and its consequences from different aspects of society, including the drug users' point of view. The users may not only be the offenders in cases of violence, but also the victims.

According to some studies, the growing wave of violence is attributable to drug use and trafficking. ${ }^{4,5}$ This trend has also been observed in other cities across Brazil. It is reasonable, therefore, to suppose that one important factor associated with violence is drug trafficking.

Taking into consideration that there are few studies that focus on crack use, this study was carried out with the objective of gathering data on the behavior and attitudes of the specific group of drug users in relation to drug abuse, violence, sex and drug trafficking in Brazil. We hypothesize that there is a relationship between crack and other drug use, involvement in violence, and behaviors that predispose individuals to the transmission of sexually-transmissible diseases.

\section{METHODS}

\section{Design and subjects}

This cross-sectional study was carried out between April 2000 and January 2001. All individuals admitted to the belowmentioned institutions during the study period were included in the analysis. Participants were individuals who had reported using illegal drugs in the past 6 months. The patients were recruited from four services available to drug abusers: the Alcohol and Drug Abuse Unit of Taipas General Hospital, the Mental Health Daycare Service of Vila Brasilândia (both part of the São Paulo State Health Department), the Primary Care for Drug Addicts Service of the Service in Universidade Federal de São Paulo (Proad-Unifesp), and the Department of Psychiatry of the Hospital Barra Funda. The number of selected patients was based on the calculated sample size for this study. Participants were interviewed by completing a standard questionnaire that has been validated in previous studies and consisted of mainly closed-ended questions. ${ }^{16}$

Interviewers, all of whom were psychologists, properly informed participants of the nature of our research. Participation in the study was voluntary, and confidentiality was guaranteed. Special attention was paid to ethical aspects of the study, and approval was obtained from the Institution's Ethic Committee (Hospital das Clinicas da Faculdade de Medicina da Universidadede São Paulo, CAPPesq. No 527/98). All participants agreed to and signed an informed consent form.

Questionnaires were first checked for their scope and consistency of information by researchers who participated in the project but who were not directly involved with administering the questionnaires. Any questions giving rise to doubts were rendered null and void by the researcher, in consultation with the interviewer. The solutions, likewise, were worked out jointly.

\section{Sample}

The sample size ${ }^{17}$ was determined, based on an estimate of HIV infection rates among drug users $(\boldsymbol{p})$ of $10 \%,{ }^{2,10}$ with a specified relative precision, $\varepsilon$, of $35 \%$, (i.e., accepting a prevalence variation of between 6.5 and $13.5 \%$ ). Within the analysis, "z" is the shape area of different significance levels, and $\alpha$ represents a confidence level of $95 \%$. Assuming a $20 \%$ refusal rate, 350 individuals were included in the sample.

\section{Violence, drug use and sex behavior}

Violence was defined as any act against others or oneself (threats, death threat, verbal arguments, physical fights, 
sexual assault, thefts, injury caused by traffic accidents) and witnessing murder among acquaintances or drug traffickers. The questionnaire included questions about the involvement with any of these types of violent acts.

The questionnaire also inquired about history of drug use (injected or other, and the frequency of use) and sexual practices, including use of condoms and number of partners. The variables studied were:

o Social characteristics: Gender, age, formal education (years), income sources, marital status, residence in the last 6 months.

o Prison and drug use: Prison history, drug use, crack use, period of illegal drug use.

o Sexual behavior: Sex worker, sex in exchange for drugs, condom use.

o Violence: Involvement in threats of physical violence, death threats, sexual violence (attacked or aggressor), involvement in verbal or physical fights (aggressor or attacked), automobile crashes, robbery to obtain drugs, murder of acquaintance (commit or witness), violence related to drug trafficking, robbery or theft.

\section{Laboratory tests}

Serological HIV diagnosis was determined through enzyme-linked immunoassay (ELISA, Roche Diagnostics) tests. A second test (third-generation test, by Ortho Diagnostics Systems) was also performed. Positive cases were confirmed by Western-blot (Sanofi-Pasteur).

\section{Statistical analysis}

Variables related to violence were dichotomous (yes/ no). Each variable was self-explanatory, for example: "verbal violence" indicates whether the subject experienced any verbal fight within the past six months. All questions were framed in the context of the previous six months. A descriptive analysis was performed, and associations between variables were verified. All associations were controlled based on the kind of drug used.

The Chi-squared $\left(\chi^{2}\right)$, Pearson and Fisher Exact tests were used to test hypotheses between categorical variables. The odds ratio (OR), capable of estimating the magnitude of the effect with $95 \%$ confidence intervals (CI), was used as an associated measure. To control for possible confounding variables, multivariate analysis was performed using stepwise forward logistic regression, with statistical significance evaluated by the likelihood ratio test, considering $p \leq 0.05$ as significant. For variables with a normal distribution, the Student's t test was used. EPI-INFO, ${ }^{18}$ and the software Statistical Package for Social Sciences (SPSS) ${ }^{19}$ was used in the development of the databases and application of the descriptive and analytical tests.

\section{RESULTS}

A total of 304 individuals were recruited for this study. Twenty-seven individuals agreed to answer the questionnaire, but refused to have their blood collected for testing. The majority of these participants said they were afraid of injections while others alleged that they had been tested on other occasions and had not received the results. Additionally, four blood samples were inappropriate for testing. Therefore, the sample was comprised of 273 subjects, all of whom responded to the questionnaire and had blood samples collected for serological analysis. The numbers of questionnaires responded to, and the number blood samples collected, respectively, for each institution, were as follows: 178 and 159 individuals from Taipa General Hospital, 9 and 9 from the Mental Health Clinic of Brasilândia, 44 and 40 from the Psychiatric Hospital of Barra Funda, and 73 and 65 from Proad-Unifesp.

\section{Social characteristics of the sample}

The sample consisted mostly of males (86\%), with an average age of 25.9 years. The social profile of the cohort, which shows gender, age, education level, sources of income, marital status, residence in the last six months, period of drug use, use of injecting drugs, and past imprisonment is summarized in table 1.

It was observed that $65 \%$ (199) of the participants reported themselves as homeowners. When asked about whether they had a specific profession, $67 \%$ (204) responded affirmatively. Of the 195 individuals who said they had been arrested once and had been unemployed before being arrested, 71\% (138) claimed to have lost their jobs due to drug-related problems, either through use or trafficking. Of the subjects who had a history of previous imprisonment (142), half were drugrelated. These 142 individuals had a period of less than a year between the first and last arrests (arrest being defined here as detainment in prison for at least one night).

With regards to source of income, 37\% (110) said that they obtained their basic income from regular employment or self-employment, while $19 \%$ (57) reported it from illegal sources or prostitution (exchange of sex for money, drugs, or goods).

\section{Sexual behavior}

Most of the participants, $98 \%$ (295), reported having had sex. $40 \%$ (118) reported having never used a condom during 
Table 1 - Demographic and social characteristics of a sample of 304 drug users under treatment from public health services in São Paulo, Brazil (2001)

\begin{tabular}{|c|c|c|c|c|}
\hline Gender & $\begin{array}{l}\text { Male } \\
261(86 \%)\end{array}$ & $\begin{array}{l}\text { Female } \\
43(14 \%)\end{array}$ & & \\
\hline Age & $\begin{array}{l}\text { Average } \\
25.9 \text { years }\end{array}$ & $\begin{array}{l}\mathrm{Sd} \\
8.4 \text { years }\end{array}$ & $\begin{array}{l}\text { Range } \\
13 \text { a } 52 \text { years }\end{array}$ & \\
\hline Formal education & $\begin{array}{l}\text { Average } \\
3.5 \text { years }\end{array}$ & $\begin{array}{l}\mathrm{Sd} \\
4.3 \text { years }\end{array}$ & $\begin{array}{l}\text { Range } \\
1-15 \text { years }\end{array}$ & \\
\hline Income source & $\begin{array}{l}\text { Formal work } \\
110(37 \%)\end{array}$ & $\begin{array}{l}\text { Illegal source } \\
57(19 \%)\end{array}$ & $\begin{array}{l}\text { Unemployment } \\
205(70 \%)\end{array}$ & \\
\hline Marital status & $\begin{array}{l}\text { Single } \\
187(62 \%)\end{array}$ & $\begin{array}{l}\text { Married } \\
43(14 \%)\end{array}$ & $\begin{array}{l}\text { Others } \\
41(14 \%)\end{array}$ & $\begin{array}{l}\text { Divorced } \\
30(10 \%)\end{array}$ \\
\hline Residence in the last 6 months & $\begin{array}{l}\text { Parents } \\
143(47 \%)\end{array}$ & $\begin{array}{l}\text { Partner } \\
69(23 \%)\end{array}$ & $\begin{array}{l}\text { Relatives } \\
39(13 \%)\end{array}$ & $\begin{array}{l}\text { Mixed* } \\
51(17 \%)\end{array}$ \\
\hline Period of illegal drug use & $\begin{array}{l}\text { Average } \\
10.9 \text { years }\end{array}$ & $\begin{array}{l}\mathrm{Sd} \\
7.7 \text { years }\end{array}$ & $\begin{array}{l}\text { Range } \\
0-39 \text { years }\end{array}$ & \\
\hline Injecting drug use & $\begin{array}{l}\text { Yes } \\
46(15 \%)\end{array}$ & $\begin{array}{l}\text { No } \\
258(85 \%)\end{array}$ & & \\
\hline Prison history & $\begin{array}{l}\text { Frequency } \\
142(48 \%)\end{array}$ & $\begin{array}{l}\text { Average }=3.2 \text { times } \\
\text { Median }=1 \text { time }\end{array}$ & $\begin{array}{l}\mathrm{Sd} \\
4.7 \text { times }\end{array}$ & \\
\hline
\end{tabular}

$\mathrm{Sd}=$ standard deviation; $*$ Mixed $=$ alone, friends, shelter.

sexual intercourse, while the remainder said they did not use condoms often.

Prostitution, defined as an exchange of money, goods, or drugs for sex, was reported in 14\% (42) of the individuals. Sex between men was reported by $13 \%$ (40) of the cohort and was significantly associated with prostitution $(\mathrm{OR}=$ 5.13, $\mathrm{CI}=2.24$ to $11.73, \chi^{2}=20.91, p<0.001$ ). Non-use of condoms during intercourse was reported by $40 \%$ (15) of these respondents. There was no significant difference regarding condom use between the groups of drug users who did and who did not mention homosexuality.

A comparison between males and females, found a higher frequency of prostitution and exchange of sex for drugs and crack cocaine use among females. Details are shown in Table 2.

\section{Sexually transmitted diseases}

Of those interviewed, $22 \%$ reported having contracted sexually transmissible diseases. Fifty-three percent (53\%)
(32) reported a history of gonorrhea, 22\% (13) of syphilis, and $12 \%$ (7) of condyloma acuminatum. Other sexually transmissible diseases, such as crab louse, Phthirus pubis, and hepatitis, were reported by $33 \%$ (20) of participants.

\section{Patterns of drug use}

The most commonly abused drug, including alcohol and tobacco, reported by participants was marijuana at $35 \%$ (106); tobacco abuse was reported by $26 \%$ (80) and alcohol by $22 \%$ (67). Excluding alcohol and tobacco, the most commonly abused drugs were marijuana (72\% (218)), cocaine (13\% (38)), and organic solvents (11\% (33)). Legal drugs were used earlier in life than illegal ones (13.6 and 15.0 years old, respectively, $p<0.001)$. Of the legal drugs, tobacco was the first to be used, followed by alcohol (12.5 and 13.7 years old, respectively, $p<0.001$ ). Of the illegal drugs, marijuana was used earlier than others (14.1 and 15.0 years old, respectively, $p<0.001)$. The average age of initiation into marijuana use was similar to that of alcohol

Table 2 - Gender differences of selected risk behaviors from a sample of drug users

\begin{tabular}{lllll}
\hline Gender & $\mathrm{n}$ & Sex workers & Drug for sex $(\%)$ & Crack use $(\%)$ \\
& & Yes $(\%)$ & Yes $(\%)$ & $204(84)$ \\
Male & 261 & $32(12)$ & $12(60)$ & $39(90)$ \\
Female & 43 & $10(23)$ & $8(80)$ & 2.68 \\
OR & & 2.11 & 6.67 & $0.06 *$ \\
$\mathrm{P}$ & & $0.06^{*}$ & $0.02^{\#}$ & $0.06^{*}$ \\
\hline
\end{tabular}

$\mathrm{n}=$ number of respondents; OR=Odds Ratio; $* \chi^{2}$ test significance; "Fisher test significance 
(no statistical difference found). Initiation of inhaled cocaine use had a later onset, compared with marijuana (18.7 and 14.1 years old, respectively, $p<0.001)$, indicating that cocaine was used mainly in adulthood, while marijuana use was initiated during the teenage years.

$80 \%$ (243) of the participants reported that they had used crack at least once in their lives. The uses of both crack and injected drugs had an early age of onset (20.5 and 19.7 years respectively, $\mathrm{p}>0.05$ ) and had been initiated by the age of 15 years for $25 \%$ of the respondents.

\section{Transition from the use of injectable drugs to crack}

In this study, 46 participants reported using injected drugs. Most of these individuals, 94\% (43), said they had stopped or reduced the use of injected drugs, and almost all became users of crack (41). Nearly half of these (21) said the change in habit was due to the use of crack. The reduction in the use of injectable drugs was observed only among crack users.

The reason given for the change from injected drug to crack by just two participants $(1 \%)$ was the lower cost of crack. The main reason for the change, reported by $48 \%$ (116) of subjects, was the use of crack by a friend or companion. Eighty percent $(80 \%)$ of participants reported initially using crack because friends were using it (243). Curiosity was the reason for the change for 51 participants $(21.2 \%)$.

\section{Social and legal problems and violence}

In relation to social and legal problems, of the 297 respondents, 97\% (288) reported some involvement with violence. Eighty four percent (84\%) (259 individuals) reported some kind of drug-related violence. In the majority of these cases $(95 \%, 245$ individuals), it was the participant of the study him/herself who initiated the violent act. Table 3 shows some violence variables and involvement with drugs among these subjects.

Of the 294 respondents, 87\% (255) reported having witnessed or knowing of a friend or acquaintance killed for drug-related reasons. The average number of deaths witnessed or known about was 5.5 (standard deviation (SD) $=6.1$ deaths, median $=2$ ) per participant. Of these, $80 \%$ (204) were users of crack. Table 4 shows the association between the different violence related variables and the use of various drugs.

The exclusive use of alcohol and involvement with violence, mentioned by 11 respondents, was only found to be related to automobile accidents $(\mathrm{OR}=3.7$, Fisher's test $p=$ 0.03). Car crash cases, reported by $34 \%$ (78) of individuals,
Table 3 - Behavioral violence variables and their relationship to drugs (use or trafficking)

\begin{tabular}{lccccc}
\hline Variables & $\mathrm{n}$ & \multicolumn{2}{c}{ Involvement } & \multicolumn{2}{c}{ Drug Related } \\
\cline { 3 - 6 } & & Yes & $(\%)$ & Yes & $(\%)$ \\
\hline Violence & 297 & 288 & $(97)$ & 259 & $(87)$ \\
Robbery or theft & 296 & 166 & $(56)$ & 175 & $(95)$ \\
Threat & 296 & 142 & $(48)$ & 111 & $(78)$ \\
Death threat & 295 & 127 & $(43)$ & 103 & $(80)$ \\
Sexual violence & 295 & 33 & $(11)$ & 23 & $(89)$ \\
Attacked & 296 & 29 & $(10)$ & 21 & $(75)$ \\
Aggressor & 295 & 6 & $(2)$ & 3 & $(50)$ \\
Involvement with fights & 297 & 259 & $(87)$ & 183 & $(72)$ \\
Verbal & 297 & 250 & $(84)$ & 169 & $(68)$ \\
Physical & 295 & 201 & $(68)$ & 129 & $(64)$ \\
Crash & 267 & 149 & $(56)$ & 78 & $(52)$ \\
\hline
\end{tabular}

$\mathrm{n}=$ number of respondents

had a marginal relationship with other drugs such as cocaine $(p=0.05)$ and marijuana $(p=0.08)$.

Using logistic analysis, the uses of different drugs were assessed as explanatory variables for different forms of violence. The results are summarized in Table 5. Verbal arguments were related to crack and mesclado when examined separately (Table 4). When adjustment for drugs were implemented, only crack remained associated with violence, showing little variation in risk (Table 5). Fights (verbal arguments and physical fights) were related to alcohol and crack when examined separately (Table 4) and remained associated when evaluated in conjunction with alcohol and crack (Table 5). There was an increase in the influence of crack when alcohol was controlled for, with an increase in statistical significance $(p<0.001)$. Involvement in both verbal and physical fights was not related to the use of any drug in particular, however, an association was observed in participants who reported using more than one drug in conjunction. Of the 233 individuals who were involved in these fights, $90 \%$ (217) had used drugs in general ( $\mathrm{OR}=2.95, \mathrm{CI}=0.84$ to 9.78, Fisher's test: $p=0.05)$.

In the sample, all users of inhalants (8) reported having stolen with the intent to obtain drugs. All of those who reported the use of tranquilizers (4) stated that most of the crimes and violence they had been involved in were related to drug trafficking. Theft was found to be related to crack and mixed marijuana use (Table 4). However, when assessing various drugs together, based on ORs, crack use was found to be more influential, mesclado less, and marijuana the same (Table 5). Robbery to obtain drugs was found to be related to the use of crack and mesclado (Table 4) when considered independently. When controlling for 
Table 4 - Drug and violence associations observed in a sub-sample of individuals (259) who reported violence linked to drug use

\begin{tabular}{|c|c|c|c|c|c|c|c|c|c|c|}
\hline Variables & $\mathbf{n}$ & $n_{1}$ & $(\%)$ & Drug & $\mathbf{n}_{2}$ & $(\%+)$ & OR & $p^{\#}$ & LCI & UCI \\
\hline Death threats & 240 & 95 & (40) & Crack & 69 & (73) & 2,92 & 0,0001 & 1,61 & 5,34 \\
\hline Threat & 242 & 101 & (42) & Crack & 73 & (72) & 2,96 & $<0,0001$ & 1,65 & 5,35 \\
\hline \multirow[t]{2}{*}{ Verbal disorder } & 242 & 156 & (64) & Crack & 102 & (65) & 2,50 & 0,0007 & 1,40 & 5,34 \\
\hline & 241 & 155 & (64) & Mesclado* & 25 & (16) & 3.12 & 0,02 & 1.07 & 9.79 \\
\hline \multirow[t]{2}{*}{ Fights } & 259 & 127 & (49) & Alcohol & 53 & $(42)$ & 2,54 & 0,0006 & 1,42 & 4,57 \\
\hline & 241 & 127 & (53) & Crack & 83 & (65) & 1.95 & 0,01 & 1.12 & 3.41 \\
\hline Crash & 232 & 78 & (34) & Alcohol & 44 & $(56)$ & 4,40 & $<0,0001$ & 2,34 & 8,30 \\
\hline \multirow[t]{3}{*}{ Robbery or theft } & 233 & 122 & (52) & Crack & 86 & (70) & 3,50 & $<0,0001$ & 1,95 & 6,30 \\
\hline & 232 & 121 & (52) & Mesclado* & 26 & (21) & 7.32 & $<0,0001$ & 2.29 & 26.01 \\
\hline & 233 & 122 & (52) & Marijuana & 49 & $(40)$ & 1.99 & 0,01 & 1.09 & 3.65 \\
\hline \multirow[t]{2}{*}{ Robbery to obtain drug } & 242 & 135 & (56) & Crack & 94 & (70) & 3,16 & $<0,0001$ & 1,79 & 5,60 \\
\hline & 241 & 134 & (56) & Mesclado* & 24 & (18) & 3.67 & 0,004 & 1.34 & 10.58 \\
\hline Murder of acquaintances & 241 & 215 & (89) & Crack & 185 & (86) & 7,19 & $<0,001$ & 2,78 & 18,75 \\
\hline Prison & 242 & 121 & $(50)$ & Crack & 83 & (69) & 2,54 & 0,0004 & 1,44 & 2,54 \\
\hline Trafficking drug related & 237 & 100 & (42) & Crack & 77 & (77) & 4,17 & $<0,0001$ & 2,25 & 7,78 \\
\hline
\end{tabular}

*Combination of cocaine and marijuana; ${ }^{*} \chi^{2}$ test significance; $\mathrm{n}=$ number of respondents; $\mathrm{n}_{1}=$ number of respondents who answered Yes to specific violence; $\%=\left(\mathrm{n}_{1} / \mathrm{n}\right) * 100 ; \mathrm{n}_{2}=$ number of respondents who answered Yes to both violence and the drug related; $(\%+)=$ percentage of $\mathrm{n}_{2}$ who related link with the specific drug; OR = Odds Ratio comparing those who said Yes versus No to this specific drug; LCI = lower confidence interval; UCI = upper confidence interval.

Table 5 - Four logistics analyses among violence variables and drugs

\begin{tabular}{llcccccc}
\hline Variables & Drugs & $\mathbf{n}$ & OR $_{\text {crude }}$ & OR & $p$ & LCI & UCI \\
\hline Verbal disorder & Crack & 241 & 2.50 & 2.28 & 0.003 & 1.31 & 3.94 \\
Fights & Alcohol & 241 & 2.54 & 2.25 & 0.005 & 1.28 & 3.96 \\
& Crack & & 1.95 & 2.10 & 0.006 & 1.23 & 3.57 \\
Robbery or theft & Crack & 232 & 3.50 & 4.23 & $<0.001$ & 1.96 & 6.34 \\
& Mesclado* & & 7.32 & 2.68 & 0.007 & 1.53 & 15.10 \\
& Marijuana & & 1.99 & 2.17 & 0.03 & 1.07 & 3.88 \\
Robbery to obtain drug & Crack & 241 & 3.16 & 2.86 & $<0.001$ & 1.67 & 4.90 \\
& Mesclado* & & 3.67 & 2.20 & 0.03 & 1.13 & 7.65 \\
\hline
\end{tabular}

$\mathrm{n}=$ number of respondents; *Also referred to as bananno $=$ combination cocaine and marijuana; $\mathrm{OR}_{\text {crude }}=$ Odds Ratio comparing those who said Yes versus No to drug use; $\mathrm{OR}=$ Odds Ratio controlled by drug; $\mathrm{LCI}=$ lower confidence interval; UCI = upper confidence interval.

the use of various drugs together, crack and mesclado ORs showed little variation (Table 5).

Violence and perpetration of crimes are related to drug trafficking (the purchasing and sale of drugs) (Table 4). No association was observed for drug trafficking and use with verbal or physical fights. Participation in drug trafficking was reported by $39 \%$ (107) of individuals, of which $92 \%$ (97) reported using crack $\left(\mathrm{OR}=4.38 ; \chi^{2}=16.29, \mathrm{CI}=1.94\right.$ - 10.21, $p<0.001)$.

\section{Serological tests and prevalence}

The prevalence of HIV infection in this sample of drug users was $6.6 \%$ (4.0 to 10.2). The use of crack showed no association with HIV infection. The use of injected drugs demonstrated a significant association with HIV infection $(\mathrm{OR}=5.2 ; \mathrm{CI}=1.7$ and 15.7 with $p=0.002)$. Having a tattoo showed no association with HIV infection. A statistically significant association was found between HIV infection and having had a blood transfusion at sometime during life (OR $=20.8 ; \mathrm{p}=0.04$, Fisher's Exact test). HIV infection was associated with other sexually transmissible diseases $(\mathrm{OR}=3.2)$. Condyloma acuminata and gonorrhea were the most closely associated with HIV infection (OR = 17.46 and 5.97, respectively, $\mathrm{p}<0.05$ ). 


\section{DISCUSSION}

Drug users are a group that deserves special attention by the health care system, due to their high risk of exposure to infections, mainly those transmitted sexually and parenterally, as a result of precarious behavior. They are also more exposed to violence. ${ }^{1,20}$

Research on drugs and violence is becoming more common in the literature, and these studies encompass knowledge from many areas, including education, medicine, sociology, criminology, epidemiology, and psychology. An understanding of the causes, correlations, and consequences of drugs and violence is necessary for implementing effective public policies for their control and prevention..$^{20,21}$ The relationship between drug use and delinquency or crime continues to be a critical research and policy issue. Research has consistently found a strong relationship between drug use and crime ${ }^{22,23}$, and it also shows that criminal behavior increases following addiction and arrests for drug offenses. ${ }^{24}$

Goldstein $^{25}$ states that drugs and violence are related to one another in three possible ways; (1) Psychopharmacologically, in which people may engage in irrational or violent actions as a result of the short-term or long-term effects of using specific drugs; (2) Economiccompulsive, in which some drug users pursue economically oriented violent crime, such as robbery, to acquire income to support their costly drug habits; and (3) Systemic, referring to the traditionally violent patterns of interaction involved in the system of drug distribution.

Compared to previously published literature, ${ }^{22-24}$ this study found a high number of subjects who had a history of previous imprisonment (142), and half of these cases were drug-related, demonstrating a close relationship between drugs and incarceration. The relationship between drug use and previous imprisonment is one way of observing the connection between drugs and violence itself.

In this study, the use of crack was associated with theft and death threats (OR $=2.97$ and 2.27, respectively). In addition, the deaths of friends or acquaintances of crack users accounted for $80 \%$ of all deaths related to drug trafficking or use in general. This tells us that violence is expressed in extreme forms among users of crack. Violence and the use of crack and other types of cocaine have previously been found to predict victimization and appear to show a causal relationship with intimate partner violence. ${ }^{26,27}$

Drug use and delinquent behavior can often be traced to factors such as poverty, educational difficulties, including poor performance in school and lack of communication with educational authorities, and high unemployment rates among other factors. ${ }^{28}$ Involvement with drugs, particularly hard drugs, among urban youths, is no longer as much about consumption or recreational behavior as it is about occupation and a career track. ${ }^{29}$ Inciardi and Pottiegers' ${ }^{30}$ studied seriously delinquent youths in Miami and found high rates of drug use among them, with almost all the youths having some involvement in the crack business. For these youths, the crack trade is attractive as a lifestyle and career track. In our study, participation in drug trafficking was reported by $39 \%$ (107) of the individuals, of which $92 \%$ (97) reported using crack. The involvement of crack users in drug dealing is extremely high, as seen in the results presented here, and should be addressed by other studies.

In this study, one of the main substances mentioned in situations involving violence was crack. This was expected, as the literature shows an increase in crack consumption in Brazil since $1990^{8,31,32}$ and an association between users of injected drugs and users of crack. ${ }^{9,12}$ It is pertinent, therefore, to assume that the prevalence of parenterally transmitted diseases, such as AIDS, may decrease with changes in the habits of these users, particularly the change from injected drugs to inhaled or smoked crack. ${ }^{33,34}$ In this study, no association was found between HIV infection and the use of crack or with having a tattoo. The lack of association between HIV infection and tattoos in this study is perhaps because no differentiation was made in the questionnaire between professional tattooists, who practice proper instrument hygeine and amateur tattooing. HIV infection was associated with a history of other sexually transmitted diseases.

The main characteristic of smoked crack is its powerful stimulating effect. This is likely what makes it a highly addictive drug, attracting increasing numbers of people to use it. ${ }^{6}$ The early initiation of drug use observed in this study (13.6 and 15.0 years), in relation to both legal and illegal drugs, shows the age range at which preventative actions should be targeted.

Most individuals who used injected drugs $(94 \%, 43)$ reported having stopped or reduced their use in this study. Almost all were users of crack (41), and 21 said this change of habit was due to the use of crack. Another feature found only among users of crack was the reduction in use of injected drugs. These data reinforce the phenomenon of a change in habit ${ }^{9,12}$ among injected drug users, who seem to find a way to replace injected cocaine with another drug. Some drug users declare that the use of injected drugs is gradually giving way to use of crack cocaine. Supposedly, the main reason behind this substitution is that the crack cocaine is not only less expensive, but also as quick and stimulating in its effects as other injected drugs. ${ }^{1-3}$ However, in $80 \%$ (243) of the respondents interviewed in this study, the main reason for crack use was not its stimulating effect, but the fact that their friends or companions were using 
the drug or had suggested it. This contrasts with the initial hypothesis of lower cost as the reason for the transition from other drugs to crack. Unfortunately, fashion trends seem to affect drug usage too.

This change in behavior should have some important effects in diminishing the prevalence of infectious disease in these groups. This study adds evidence to the assertion that the transition from injected to non-injected drugs appears to be a relatively stable behavior change for many former injectors, who report a decade or more without injecting. Developing a greater understanding of the transition from injection to stable non-injection drug use may provide insights into the natural histories of drug use and addiction. ${ }^{35}$

Another fact observed is the change in the epidemiological picture with regard to diseases. A decrease of AIDS cases among individuals infected by transfusion has been observed since 1990, with declines from $2.7 \%$ in 1990 to $0.4 \%$ in 1997 and $0.1 \%$ by 1998 and 1999 in São Paulo. ${ }^{26}$ It is known that injected drug users represent the most important group involved in this form of transmission. ${ }^{27}$ Injected drug users, since 1990, now represent $15 \%, 6 \%$ and $3 \%$ of transmitters respectively. ${ }^{26,27}$

A high prevalence of prostitution was observed - 14\% (42) of the participants - and also of homosexuality - $13 \%$ (40). Furthermore, a correlation was observed between the two practices (odds ratio $=5.13$; confidence interval 2.24 to 11.73; $\left.\chi^{2}=20.91, p<0.001\right)$. A similar finding was reported by Ericson (2000) among poor women who were users of crack and who were in, or became involved in, the sex trade. ${ }^{36}$

Many studies have verified that relationships with parents, supervision, family links, school and community, and social interventions act as protective factors against the negative effects of exposure to violence. ${ }^{21}$ However, these were not addressed in our study. We believe it is essential to include protective factors in ongoing and future research models of violence analysis, so that intervention strategies can be formulated.

On cross-sectional studies, the measure of association that would be most appropriate is "rate of prevalence". In this case, the choice to use odds ratios (OR) was based on the fact that it is widely used for this type of study, with advantages and disadvantages. Among the advantages are greater simplicity in calculations and ease of comparison with previous studies. As for the disadvantages, there is often an overestimation of risk, which is slowly and gradually expanded to the extent that the prevalence of these values assumes values greater than $10 \% .^{34}$

It is possible that there is a bias in the participant selection in this study, since gathering subjects required contacting various health services. However, the fact that the sample was only distributed among public health services means that the spontaneous demand for the service was probably homogeneous. Information bias was minimized by standardizing the questionnaire and training the research staff.

The study design also has limitations. Although our sample had many more men $(86 \%)$ than women $(14 \%)$, this does not necessarily reflect the reality of drug users in the community. However, there was no trend in relation to the recruitment of participants that would explain the higher participation of men. Some variables, such as prostitution, exchange of drugs for sex, and the use of crack, were more sex-related and proportionately more common in women.

It is important to note that these findings cannot be extended to the population as a whole. However, the information presented here outlines the importance of carrying out studies that include a good methodological approach and standardized questionnaires. This will ensure that formulations and implementations of policies for prevention and treatment of drug abuse as a whole, and crack in particular, can be conducted in an appropriate way.

\section{CONCLUSIONS}

The prevalence of HIV among users of crack, in this group, was high $(6.6 \%)$, with no significant difference between users of crack and users of other drugs. However, some patterns of behavior appear to be modified by the use of crack. Crack was associated with decreased frequency of sexual relations, obtaining drugs by means of prostitution, and interruption or decrease in the use of injected drugs. The data presented here help strengthen the argument that there is a transition from the use of injected drugs to inhaled or smoked drugs. Crack has shown itself as an alternative to the use of other drugs. The transition from injected to noninjected drug use appears to be a relatively stable behavior change that provides insights into the natural histories of drug use.

According to our results, verbal arguments, physical fights, threats, death threats, theft, and drug trafficking represent the majority of crimes or types of violence in which crack users are involved. Others, such as car accidents, are explained by involvement with alcohol. In view of these results, regardless of the limitations of this study, it is important to alert the authorities and society in general, to violence surrounding drug trafficking, with special attention to crack cocaine.

\section{ACKNOWLEDGEMENT}

This research was finantially supported by Fundação de Amparo à Pesquisa do Estado de São Paulo (Fapesp), grant number: 98/11630-3. 


\section{REFERENCES}

1. de Carvalho HB, Mesquita F, Massad E, Bueno RC, Lopes GT, Ruiz MA, et al. HIV and infections of similar transmission patterns in a drug injectors community of Santos, Brazil. J Acquir Immune Defic Syndr Hum Retrovirol 1996;12:84-92.

2. Des Jarlais DC, Casriel C, Friedman SR, Rosenblum A. AIDS and the transition to illicit drug injection--results of a randomized trial prevention program. Br J Addict 1992;87:493-8.

3. Des Jarlais DC, Friedman SR. Critical issues regarding AIDS among injecting drug users. Bull Narc. 1993;45:61-75.

4. Lipton DS, Johnson BD. Smack, crack, and score: two decades of NIDA-funded drugs and crime research at NDRI 1974-1994. Subst Use Misuse. 1998;33:1779-815.

5. Shannon K, Rusch M, Shoveller J, Alexson D, Gibson K, Tyndall MW, et al. Mapping violence and policing as an environmental-structural barrier to health service and syringe availability among substance-using women in street-level sex work. Int J Drug Policy. 2008;19:140-7.

6. Koutouzis M, Perez P. Observatoire geopolitique des drogues. Atlas mondial des drogues. Paris; PUF, 1996.

7. Hamid A. The development cycle of a drug epidemic: the cocaine smoking epidemic of 1981-1991. J. Psychoactive Drugs. 1992;24:33748 .

8. Dunn J, Laranjeira RR, Da Silveira DX, Formigoni ML, Ferri CP. Crack cocaine: an increase in use among patients attending clinics in São Paulo: 1990-1993. Subst Use Misuse. 1996;31:519-27.

9. Nappo SA, Galduróz JCF, Noto AR. Uso do "crack" em São Paulo: fenômeno emergente? [Crack use in Sao Paulo city: an emergent phenomenon?]. Rev ABP-APAL. 1994;16:75-83.

10. Dunn J, Laranjeira R. Cocaine--profiles, drug histories, and patterns of use of patients from Brazil. Subst Use Misuse. 1999;34:1527-48.

11. Gikas R, Fruchtengarten L, Duarte J, Wong A. Prevalência de intoxicações por drogas de abuso na região metropolitana de SP, período de junho de 1996 a junho de 1997. Rev Bras Toxol. 1997;10:31.

12. Bueno R, Carvalho HB, Lopes GT, Mesquita F, Andrade T, Bastos FI, et al. Differences in social demographic pattern and risky behavior of Brazilian IDUs. In: 8th International Conference on the Reduction of Drug Related Harm in Paris; 1997.

13. Lopes GT, Carvalho HB, Burattini MN, Massad E, Bueno R, Mesquita $\mathrm{F}$, et al. Social-demographic patterns and trends in risky behaviors of IDUs in the city of Santos, São Paulo, Brazil. In: 8th International Conference on the Reduction of Drug Related Harm in Paris; 1997.

14. Beato Filho CC, Assunção RM, Silva BFA, Marinho FC, Reis IA, Almeida MCM. Conglomerados de homicídios e tráfico de drogas em Belo Horizonte, Minas Gerais, Brasil, de 1995 a 1999. [Homicide clusters and drug traffic in Belo Horizonte, Minas Gerais, Brazil from 1995 to 1999]. Cad Saúde Publica = Rep Public Health. 2001;17:1163-71.

15. Inciardi JA, Surratt HL. Children in the streets of Brazil: drug use, crime, violence, and HIV risks. Subst Use Misuse. 1998;33:1461-80.

16. World Health Organization. Programme on substance abuse. Multicity study on drug injecting and risk of HIV infection. World Health Organization; 1994. Available from: http://whqlibdoc.who.int/hq/1994/ WHO_PSA_94.4.pdf. Accessed in 2007 (Oct 22).
17. Lwanga SK, Lemeshow S. Sample size determination in health studies: a practical manual. Geneva: World Health Organization, 1991.

18. Dean AG, Dean JA, Coulombier D, Burton AH, Smith, DC.; Brendel, KA. Epi Info Version 6.04. A word-processing, database and statistics program for public health on IBM. Compatible microcomputers. Atlanta: Centers for Disease Control and Prevention; 1996.

19. Norusis MJ. SPSS Advanced Statistics, Release 6.1. SPSS Inc. Marketing Department. Chicago; 1994.

20. De La Rosa M, Lambert, EY, Gropper B. Drugs and violence: causes, correlates, and consequences. NIDA Research Monograph 103. Rockville: National Institute on Drug Abuse; 1990

21. Benetti SPC, Gama C, Vitolo M, Silva MB, D’Ávila A, Zavaschi ML Violência comunitária, exposição às drogas ilícitas e envolvimento com a lei na adolescência. Psico. 2006;37:279-86.

22. Chaiken JM, Chaiken MR. Varieties of criminal behavior. Santa Monica: Rand; 1982.

23. Wish ED, Gropper BA. Drug testing by the criminal justice system: methods, research, and applications. Washington: National Institute of Justice; 1989.

24. Anglin MD, Speckart G. Narcotics use and crime: a multisample, multimethod analysis. Criminology. 1988;26:197-233.

25. Goldstein PJ. The drugs/violence nexus: a tripartite conceptual framework. J Drug Issues. 1985;15:493-506.

26. Brasil. Secretaria de Estado da Saude. Boletim epidemiológico C.R.T. - DST/AIDS Ano I No 01 - NOVEMBRO 2001. Available ftp://ftp.cve. saude.sp.gov.br/doc_tec/outros/bol_crt2002.pdf Accessed in 2008 (Oct 22).

27. Brasil. Ministério da Saúde. DST-AIDS. Boletim epidemiológico. Junho a agosto de 1999. Ano XII No 03 - Semana Epidemiológica - 22/1999 a 34/1999 Available from:http://www.aids.gov.br/udtv/boletim_jun_ ago99/tabelas_notificacao.htm Accessed in 2008 (Oct 22).

28. Gibbs JT. Black adolescents and youth: an endangered species. Am J Orthopsychiatry. 1984;54:6-21.

29. Preble E, Casey J. Taking care of business: the heroin user's life on the street. Int J Addict 1969;4:1-24.

30. Inciardi JA, Pottieger AE. Kids, crack, and crime. J Drug Issues 1991;21:257-70.

31. Departamento De Investigação sobre Narcóticos (Denarc). Relatório anual de 1994. São Paulo, Denarc, 1995.

32. Araújo Lima LC. O vício e a violência: o cotidiano do crack e as narrativas do vício. [dissertation]. São Paulo: Pontificia Universidade Catolica, PUC/SP; 1997.

33. El-Bassel N, Gilbert L, Wu E, Go H, Hill J. Relationship between drug abuse and intimate partner violence: a longitudinal study among women receiving methadone. Am J Public Health 2005;95:465-70

34. Fletcher RH, Fletcher SW, Wagner EH. Epidemiologia clínica: elementos essenciais. $3^{\mathrm{a}}$ edição. Porto Alegre: Artmed; 2003. 
35. Des Jarlais DC, Arasteh K, Perlis T, Hagan H, Heckathorn DD, Mcknigh $\mathrm{C}$, et al. The transition from injection to non-injection drug use: longterm outcomes among heroin and cocaine users in New York City. Addiction 2007;102:778-85.
36. Erickson PG, Butters J, McGillicuddy P, Hallgren A. Crack and prostitution: gender, myths, and experiences. J Drug Issues. 2000;30:767-88. 